\title{
1. State of the field: the family and marriage in China
}

\author{
Xiaowei Zang and Lucy Xia Zhao
}

How the family can be best defined is a subject of debate among scholars. While we acknowledge the different definitions of the family, we consider the family as a basic unit of human society to support and regulate human sexual interaction, reproduction, childrearing and socialization, elderly care, and other important functions. Its structural form and strength vary greatly across cultures and time. Family ties are different from other types of intimate relationships such as friendship and colleagiality. Non-family bonds do not carry the family functions mentioned above, and can be broken at any time. Family ties exist as an end in themselves (Cox, 2008: 30-31). For convenience, we use 'the family', 'the family institution', and 'the household' interchangeably in this chapter.

The study of the family and marriage in China is interesting given profound changes in fertility transition, household structure, mate selection, divorce, old-age support, and so on, since the nineteenth century. Major causes of the changes include influence from Japan and the West before 1949, post-1949 industrialization and urbanization, the political campaigns carried out by the Chinese Communist Party (CCP) between 1949 and 1976, and post-1978 market reforms and socioeconomic development (Zang, 2007). Post-1978 government policies have accelerated economic growth, which according to Davis (2014: 26) have inadvertently fostered demographic challenges in the People's Republic of China (PRC):

Filial sons and daughters sent back remittances, parents cared for migrants' children and invested in their children's marriages, and families with four grandparents, two parents, and one child $(4+2+1)$ pooled resources to continuously improve a family's material well-being. But now the demographic challenges have further intensified and the question arises: can the state adopt new policies that will allow the prototypical $4+2+1$ families created by the one-child policy to thrive through 2030 ?

To partly address this question in this chapter, we first review the English literature on a few selected aspects of the family institution and marriage in China. Next, we summarize the outline of each chapter that follows. As readers can see, the topics discussed in this edited volume include love and marriage, educational endogamy, family planning, son preference, the marriage squeeze, family decision-making power, filial piety and old-age support, intermarriage and intercultural dating, international adoption from mainland China, and many more. It also includes a chapter on Hong Kong and another on Taiwan.

\section{FAMILY STRUCTURE}

It is widely believed that in traditional China, many people lived in large, multigenerational families. An extended household could consist of five generations living together under one roof, sharing one common purse and one common stove, under one 
family head. Some scholars have asserted that 'the so called large, extended, or joint form of the family was commonplace' in China (Cohen, 1976: xiii). Wolf (1985) found that in nine districts in northern Taiwan between 1906 and 1946, more than 70 per cent of the residents lived in stem families in which parents lived with a son, his spouse, and his children. Wolf's findings are supported by research on mainland China in the pre-1949 era by Lee and Gjerde (1986) and Lee and Campbell (1998).

Other scholars have argued that, in reality, extended families with five generations living together were as a matter of fact uncommon. Eastman (1988: 16) estimated that the proportion of such extended households might have reached 6 or 7 per cent in the past. Lang (1946: 10) claimed that "the joint family is not and never was the "normal" type of Chinese family' in the pre-1949 era. Freedman (1979: 235) asserts that the large joint family 'could not have existed as a common form of the family because of the statistical fact that the average size of the domestic family was between five and six souls'. Goode (1963: 296) thus contended that the large multigenerational family appeared to have been 'the ideal exception' and 'a luxury'.

It seems that most urban Chinese resided in nuclear families after the 1930s due to rapid social changes and the family revolution since the nineteenth century. Increasing urbanization and industrialization since 1949 have contributed further to the movement toward conjugal family structure. By 1900, more than half of urban families took the nuclear form; by the 1980s this grew to two-thirds (Zang, 1993). Extended families with three generations constituted only 18.3 per cent of the households in 1990 and 19.5 per cent in 1995, respectively. In 2000, a small proportion of 20.1 per cent of all households in China had at least one elderly member aged 65 or above (Zeng and Wang, 2003). Xu and Yan (2014: 31) claim that the nuclear family is the most common form; the single-person family, single-parent family, remarried family, and childless family 'are a fraction of the population', and there are also extended households due to their function in the provision of elderly care by adult children and of childcare and family services by parents. In multi-generation families, adult women often take care of elderly parents in both urban areas (Liu et al., 2010; Yang et al., 2016) and rural China (Qiao et al., 2015). Co-residing elderly parents, if they are healthy and able, take over household tasks from adult women, helping to reduce gender differences in work-related activities in both urban and rural China (Feng et al., 2015; Qiao et al., 2015).

To a certain extent, family structure is related to family size. Households in traditional China are assumed to be fairly large partly because some of them were extended and partly because of high birth rates. High fertility was a major weapon to reduce the negative effect of high child mortality rates in the pre-1949 era. Before the 1950s, the average household in China had more than 5.3 people ( $\mathrm{Lu}, 2014)$. There has been a gradual movement toward small family size after 1949 (Bradbury et al., 2014: 78). In particular, the average household reduced in size from 3.5 in 1990 to 2.91 in 2008 (Lin, 2014: 146), and then to 2.88 in 2010, 2.98 in 2013, and 2.97 in 2014 (Statista, 2016).

The major change in family size apparently took place after the implementation of the one-child birth control policy in 1979. Household size in China is also closely correlated to family income. According to the National Bureau of Statistics of China, in 2012, households with the lowest income had an average size of 3.3 people, while households with the highest income consisted of 2.52 people only (Statista, 2016). In addition, three demographics have stood out in the reduction in family size: unmarried young workers, couples 
who have delayed or forgone childbirth, and elderly empty-nesters (Lu, 2014). Forty per cent of the nationwide total Chinese households, 160 million, now consist of only one or two people. In the decade between 2000 and 2010, when urbanization was at full throttle, the number of solo households doubled and the number of two-member households increased by 68 per cent. Last but not the least, fertility transition, to be discussed below, is also a main reason that family size in China is shrinking.

\section{FERTILITY TRANSITION}

There was a rapid and sharp fertility decline in China - from total fertility rates of approximately six births to two - between 1970 and 1990. One child is now the dominant mode of family size in metropolitan areas (Cai, 2010: 422, 434; see also Cai, 2013; Liu and Zhang, 2009; Zheng et al., 2009; Retherford et al., 2005). According to China's 2000 census, the total fertility rate (TFR) in the year 2000 was 1.22 children per woman. Yet it is widely believed that this figure is inaccurate due to fertility under-reporting that has plagued China's censuses for many years (Morgan et al., 2009: 605). Retherford et al. (2005) suggest that the TFR in 2000 should be between 1.5 and 1.6 children per woman. Morgan et al. (2009) similarly claim that the TFR was likely to be in the range of 1.4 to 1.6 per woman, using data from both the 1997 National Population and Reproductive Health Survey and the 2001 Reproductive Health and Family Planning Survey. Wu et al. (2014: 13) document the differences in fertility among different cohorts of Chinese couples: 3.30 children for those married before 1971, 2.23 for those married between 1971 and 1980, 1.75 for those married between 1981 and 1990, and 1.14 for those married after 1990. Bradbury et al. (2014: 74) conclude that China had birth rates below replacement levels in 2010.

China's below-replacement fertility has social costs and long-term demographic effects such as rapid population ageing, distorted sex ratios, and changes to the family and kinship system. For example, China has experienced an unprecedented rise in the sex ratio at birth (ratio of male to female births). There are allegedly far more male live births than female live births as compared to the numbers in most other human populations. China's sex ratio at birth was 108.5 in the 1982 census, 111.3 in the 1990 census, 116.9 in the 2000 census, and 118.6 in the 2010 census. A large-scale study of 4764512 people in all of China's 2861 counties shows that sex ratios were high across all age groups in both urban and rural areas, but they were highest in the age group of 1-4 years, peaking at an average of 126 in rural areas. Six provinces had sex ratios of over 130 in the age group of 1-4 years. The sex ratio at birth was close to normal for first births but rose steeply for second births, especially in rural areas, where it reached 146 . Nine provinces had ratios of over 160 for second births. The highest sex ratios were found in the provinces that allowed rural inhabitants a second child if the first was a girl. This is partly why one study finds that in 2005, males under the age of 20 exceeded females by more than 32 million (Zhu et al., 2009; also Feng et al., Chapter 11 in this volume; Gietel-Basten, Chapter 12 in this volume; Li et al., Chapter 9 in this volume).

While the sex ratio imbalance situation is grave, there have been exciting developments in recent years. Sun and Zhao (2016) argue that the 2001 divorce reforms have empowered Chinese women within marriage, and enabled them to avoid health-damaging sex-selective 
abortions. As a result, the likelihood of having a son after a first-born daughter decreased by 8.1 percentage points, which amounts to a reduction of 11.7 per cent compared with the prior proportion of male children. The effect of the 2001 divorce reform is stronger in provinces with more lenient family planning policies governing fertility in the next marriage. Moreover, in October 2015, the PRC government officially abandoned the one-child policy, allowing each couple to have two children.

\section{MARRIAGE}

In most historical Chinese populations, virtually all women were married by age 30 (Coale, 1989: 834). Not all men were married, and their marriage age varied widely, depending primarily on their financial status. Marriage in traditional China had little to do with romance and love. It was instead conceived as the transfer of a woman from her family to that of her husband, and the bride's family justifiably demanded financial compensation. A man could not get married unless he was able to pay for a bride (Zhou, 2006). The prevalence of paying a bride price was partly related to the patrilineal family system that was male-centred, which discouraged parents from raising a daughter since she would be married 'out of the family', thereby representing a loss in the parents' investments in her. A preference for boys and discrimination against girls led to an imbalance in the population's sex structure in traditional China (Jiang and Sánchez-Barricarte, 2012: 3), and the gap between supply and demand for brides quickly resulted in a steep increase in competition for and the price for a bride (that is, dowry) in the marriage market. Some families purchased a young girl as the future daughter-in-law (Wolf, 1980), which can be seen as their investment strategy in meeting the unpredictable challenges and avoiding a large dowry in the marriage market.

In the case of first marriage, the groom's parents negotiated with and paid the agreed bride price to the bride's parents, which gave them the right and power to arrange the marriage of their son. Their power was also derived from the fact that they 'owned' their child, just like the bride's parents. Unsurprisingly, young people had very little say, either about timing or partner, in their marriage. The groom and the bride often had not met each other until the wedding day, so that they would not spoil the business transition between their parents. All this gave the parents effective control over the marriages of their offspring to continue the family line (Parish and Whyte, 1978).

There have been significant changes in the marriage institution in modern China. One study finds that the mean age at first marriage increased from about 17.5 years around 1930 to 18.5 in the 1940s, to about 20 in 1970, and to about 23 in 1980 (Coale, 1989: 834). Another study (Zang, 1993) shows that about 10 per cent of the brides during the 1930s were younger than 15 years old; by 1950, early marriages had reduced significantly. In 1994, the average marriage age for women at first marriage was 23.

Freedom in choosing one's partner has also increased in China since 1900. More than half of all marriages were arranged by parents between 1900 and 1938; by 1982, arranged marriages had almost disappeared. By then, four in every five couples married of their own volition. Many young people found their partners themselves. For others, introduction by co-workers, supervisors, friends, and relatives was an important way of getting to know the opposite sex before 1978. These changes were brought about by the combined 
forces of industrialization, urbanization, mass education, and government policy (Zang, 1993). Globalization, the Internet and other new developments have strengthened the trend toward free love and romance among young people in the post-1978 era.

Love and romance are a necessary but not sufficient condition for a lasting relationship in contemporary China (see Gaetano, Chapter 8 in this volume). One study (Jackson et al., 2006) reports that fairy-tale ideals are a major theme among American young adults but not among Chinese young adults. Another study (Buss et al., 1990) examines 37 countries and claims that the participants in the Chinese sample differed from those in other samples in paying more attention to health, chastity, and domestic skills, but giving less value to traits such as mutual attraction, dependability, and sociability. It is possible that in China, family-related characteristics of a potential mate are more important than romantic love (Dion and Dion, 1993). Not surprisingly, family influence is still important in marriage decisions in China (Pimentel, 2000). Young Chinese place significant weight on their family's and friends' opinions. Approval by parents, friends, and other family members are important for them to decide if they want to marry their lovers (Zhang and Kline, 2009).

Status similarity is also a key factor in the choice of a marriage partner. Successful matchmaking in traditional China was based on the principle of 'one door matches another door'; that is, the two families were of similar socioeconomic status. A gobetween would not waste her energy and time to fix a match for a man with a woman unless their families were of equal socioeconomic status. This pattern persisted into Mao's China till the Cultural Revolution of 1966-76 when state policies deliberately lowered the value of educational credentials in the marriage market in a quest for greater degrees of equality in China. As a result, the strength of educational homogamy in urban China was weakened during the Cultural Revolution (Song, 2009).

Assortative mating has come back in the post-1978 era, as people increasingly married others similar to them with respect to education. The percentage of couples with the same years of schooling increased from 50 per cent to 65 per cent between the 1985-89 marriage cohort and the 1995-2000 cohort. At the national level there was an overall 15-point increase in the percentage of educational homogamy from 1970 to 2000 . The odds of crossing two or three educational barriers were cut in half between 1980 and 2000. Thus, for college graduates in urban areas, the odds of marrying junior high school graduates (that is, crossing two educational barriers) shrank from 0.11 to 0.02 , and the chances of marrying a person with less than six years of schooling (that is, crossing three educational barriers) in the late 1990s were only one-tenth of the odds in the late 1970s. There appears to be a greater degree of social closure among college graduates than among the groups with lower levels of educational attainment in China (Han, 2010).

Coupled with rising educational homogamy, there has been a decline in marital age homogamy in the post-1990 era. Intensified economic pressure and rising consumerism have increased women's desire to marry men who are more economically established, and usually older, compared to less financially secure young men. As a result, age hypergamy (younger women marrying older men) maintains status hypergamy in China. A continued trend in age hypergamy implies a future male 'marriage squeeze' for men of low socioeconomic status (Mu and Xie, 2014; see also Song et al., Chapter 7 in this volume).

The male marriage squeeze refers to the phenomenon of difficulties and failures experienced by some men in finding a female in the marriage market because of 'the imbalance in the numbers of marriageable males and marriageable females at the same ages or close ages' 
(Huang, 2014: 1643). The male marriage squeeze is typically related to patriarchal and patrilineal societies because of discrimination against women (Huang, 2014; Jiang et al., 2011) and has always been part of the marriage market in China (Jiang and Sánchez-Barricarte, 2012: 2-3). An optimistic view suggests the reduction of the male marriage squeeze since 1949. The data of both the 1953 census and 1964 census show 12 million excess males aged older than 20 years, which was 8.5 per cent of the total male population at marriageable ages in 1964. The number of excess males in the 1982 census, about 20 million, was larger than that in the 1964 census, but the proportion of the excess males in the 1982 census was less than 8.4 per cent, which was nearly the same as that in the 1964 census. The increase in number in 1982 is largely due to the fact that the total population had increased. The 1990 census data show that the total number of excess males reached 22 million in 1990, and the proportion of the excess males over 22 to the total number of males over 22 was 7.3 per cent. According to 2010 census data, the number of excess males in 2010 was 14 million, and their proportion dropped to 3.1 per cent (Huang, 2014: 1651-1653; see also Eklund and Attané, Chapter 10 in this volume; Li et al., Chapter 9 in this volume).

There are some doubts about the severity of the predicted male marriage squeeze in China due to the uncertainty about the high sex ratio at birth since the 1980s (Huang, 2014: 1646). This is reinforced by the different predictions from different studies on the number and proportion of excess males in the marriage market of China, and the differences come into being partly because the different studies use different data and methods, including different measures of marriage squeeze (ibid.: 1646-1647). Finally, Huang (2014: 1654) argues that the number of the surplus males will decrease after the middle of the 2040s: 'In 2070, the surplus males born between 1983 and 2030 will drop to less than 1 million and their proportion in all males older than 22 years will be less than $2 \%$.'

Recently, some people have asserted that there is also a female marriage squeeze. The term shengnü (剩女) has become frequently used in public. The so-called female marriage squeeze occurs not because there are surplus women in China, but because there is an alleged increase in the number of women who are well educated, have a high income, are at their most marriageable ages, and allegedly refuse to compromise their mate selection criteria (Fincher, 2014; Huang, 2014; To, 2013). In 2007, the PRC Ministry of Education released an official statement to define shengnü as unmarried women over the age of 27 , and added it to the national lexicon (Fincher, 2012). The term shengnü has been greatly popularized by a comedy television series titled My Eldest Girl Should Get Married (大 女当嫁) premièred on the state-run channel CCTV-8 in 2010. This media frenzy is both unusual and suspicious in a country where men greatly outnumber women, as mentioned above, and where one in five women between the age of 25 and 29 remain unmarried, whereas one in three men in that age range are unwed (Magistad, 2013). Ji and Yeung (2014: 1678-1679) argue that Chinese women who choose to remain single voluntarily are derogated by society as 'leftover' females because of the traditional social norm of status hypergamy; that is, women marry up in terms of income, education, and age (see also Berman et al., 1981; Sontag, 1972). Ji (2015) discusses the social obstacles these Chinese women face when they negotiate the contradictions in marriage and career development: (1) parental pressure; (2) a gender double standard of ageing; (3) forced socioeconomic hypergamy; (4) the importance of compatible family backgrounds; (5) efforts to balance their own independence with the support they are expected to provide to family and men; and (6) conflicting gender ideologies. 
Qian and Qian (2014: 1337) argue that the rapid rise in women's education, coupled with persistent traditional gender roles, contribute to low marriage rates among older, highly educated Chinese women. As education increases, the likelihood of marriage increases among men but decreases among women, especially among those over age 30. More and more marriages involve better-educated, older men and less-educated, younger women. This is partly because Chinese women value economic prospects in a potential mate, as noted above, and that women with high earning potentials and career aspirations may not find marriage beneficial, due to clashes between career and family. Highly educated women may not want to compromise their careers when they search for marriageable partners. In addition, these women are more likely than highly educated men to support gender egalitarianism. Highly educated men with less egalitarian gender attitudes can marry down in terms of both age and educational attainment, whereas highly educated women cannot. As a result, the marriage pool for highly educated women becomes small due to a shortage of men with a similar level of education. 'This contributes to a "marriage squeeze" for highly educated women in urban China' (Qian and Qian, 2014: 1341; see also Simpson and De Lacey, 2013; Subramanian and Lee, 2011).

However, it is not a forgone conclusion that a female marriage squeeze is sweeping through China. To (2015) does not find evidence that unmarried Chinese professional women withdrew from the marriage market. As a matter of fact, they actively dealt with marriage timing and partner choice from the perspective of filial piety. While 'deferring' to parents' matchmaking demands, they negotiated their own partner choice. Ji and Yeung (2014: 1662, 1678-1679) show that almost all Chinese women are married by age 35-39. Female university graduates may delay marriage for career development and can afford to spend more time searching for a compatible mate compared to less-educated women, due to their relatively favourable financial situation. In any event, most of them eventually marry by age 35 . See Gaetano (Chapter 8 in this volume) for more information about 'leftover' women in China.

Regardless of what may happen with regard to the male marriage squeeze or the socalled female marriage squeeze, it seems there will be a huge number and increasingly high proportion of elderly bachelors in the years to come. Huang (2014: 1655) predicts that the number of bachelors older than 60 years will rise from 610000 in 2043 to 9.68 million in 2058, when 33 per cent of the bachelors will be older than 60 years. After 2058, the number of bachelors older than 60 will decrease but their proportion compared to all bachelors will increase to 47 per cent. China will face a major challenge in the provision of elderly care such as the supply of nursing homes and pension arrangements.

\section{PROVISION OF ELDERLY CARE}

The 1996 Law of the People's Republic of China Regarding the Protection of the Rights and Interests of the Elderly defines the elderly as those in the age group of 60 years and above. It is claimed that in China:

25 per cent of the total population will be aged 60 and above by 2030, and the population of those aged 65 and over is projected to increase to 15 per cent, also by 2030. Meanwhile, the 
worker retiree ratio is expected to fall from 8.6 to 2.3 in 2010 and to 1 by 2030. In addition to the dramatic increase in the number of elderly in the Chinese population, life expectancy has increased from 68.55 years in 1990 to 71.40 years in 2000. (Lin, 2014: 145)

It is estimated that by 2050 China could have a staggering 115 million elderly citizens over 80 years old (Hou and Li, 2011: 514). China faces an overwhelming and urgent need for long-term care (Shen et al., 2014: 679; see also Hou and Li, 2011).

While state policy is commonly regarded as a key determinant of the provision of elderly care in China, several aspects of family and marriage institutions discussed above, such as small family size, fertility transition, and a large number of elderly bachelors also have a direct bearing on elderly care (Li, 2005; Lin, 2014). For example, Chen and Short (2008) find that living alone is associated with lower subjective well-being for the elderly. Co-residence with immediate family (spouse or children) is associated with positive subjective well-being. Compared to living with a son, the traditionally dominant type of living arrangement, co-residence with a daughter appears to be positively linked to the emotional health of the oldest-old. Given the importance of family and cultural context to the subjective well-being of the elderly, the government updated the 1996 law on 1 July 2013, requiring children who are not living with their parents to visit their elderly parents regularly.

Zhang et al. (2015) find that economic conditions, chronic health status, living arrangements, social activity participation, and caring for grandchildren are factors that are most important to the health of elderly Chinese. This is true for both self-rated health and psychological well-being. The beneficial effects of participation in social activities are particularly salient for elderly women and for the 'old-old', whereas the salutary effects of caring for grandchildren are more substantial for elderly men and for the 'young-old'. Feng et al. (2015) report that living with a spouse, maintaining financial independence, and receiving care support from any source is associated with higher survival rates for elderly people. Separate analysis focusing on urban elderly and rural elderly revealed similar results in a broad sense. There is a larger difference between those receiving care support from family or social services and those not receiving care support in urban areas compared to those in rural areas. Those who cannot pay medical expenses are least likely to survive. The level of economic development in a province has no significant effect on the survival rate of the elderly people for the whole sample, or on that of the elderly people in urban areas.

According to Hou and Li (2011), urban elders enjoy better healthcare than their rural counterparts. With the support of the central government, 90 per cent of the rural population now receive some form of basic health insurance coverage. The issue is the reimbursement rate. For outpatient care, the reimbursement rates are roughly 40 per cent and 32 per cent for the urban and rural patients, respectively. The reimbursement rate for inpatient care is even worse, averaging around only 10 per cent, which is a greater burden on elders in rural areas than on those in urban areas, given their income differences.

Elderly poverty can be understood not only in terms of objective well-being indicators such as income and consumption levels, but also in terms of subjective indicators which reflect how a person feels. Wang et al. (2011) estimate that the incidence of subjective wellbeing poverty (SWP) among the Chinese rural elderly population in 2006 was 9.7 per cent, about 4.2 times as much as that of the country's total rural population in the same year, 
which was 2.3 per cent. More than 16 per cent of the rural elderly population and 11.5 per cent of the urban elderly population rated their life satisfaction as poor or very poor.

One possible reason for the poor ratings by the rural elderly is the rural-to-urban migration, which has separated adult children who go to cities to work, from their ageing parents who stay in their villages. As a result, there are significant challenges to traditional patterns of familial support for the rural older people. Those living alone without any adult children in the village are most at risk (Connelly and Maurer-Fazio, 2016). Precisely, it is the breakdown of the webs of interdependence and reciprocity rather than the event of migration that has negative effects upon old-age care for the seniors in the household. The members of a rural household across different geographical locations have to work together to build and maintain the collective welfare of the family (Liu, 2014).

\section{CHAPTER OUTLINES}

We have touched upon some aspects of the family and marriage in China. There are other aspects of the Chinese family institution which are no less important than the ones we have examined above. We thus sought help from the contributors to this edited volume to provide an outline for each chapter below, to serve as a quick reference point for readers interested in the Chinese family.

In Chapter 2, Dudley L. Poston uses demographic transition theory (DTT) to examine how demographic change influences marriage and family in China. He charts China's progress through the transition, starting when Mao Zedong established the People's Republic of China, and carrying through to around 2015. He then discusses the types of changes in marriage and family that are likely to occur in societies that have transitioned to low fertility, focusing specifically on age at first marriage, cohabitation, age at first intercourse, premarital intercourse, masturbation, and unbalanced sex ratios at birth. He presents and analyses empirical data from China on each of these six features of marriage and family, along with more limited data for the United States and a few other countries. He argues that changes in China in the levels and prevalence of these six features of marriage and the family have all been influenced by, or have been a consequence of, the changes in China as it has transitioned from high fertility rates in the 1960s to a very low rate today.

In Chapter 3, Yan Ruth Xia and Anqi Xu discuss the changing family system in urban China. They show connectedness and interactions between Chinese urban family structure and different levels of the social contexts and explain cultural, social, and economic forces directly or indirectly influencing the Chinese family. Family structure is viewed as flexible and interactive with its environment. Culture, policy, economy, and housing reform all play a role in shaping the experience of urban Chinese families. The social changes in housing, education, and the job market have brought opportunities, choices, and wealth, but at the same time posed stress to Chinese families during the social transition. Contemporary Chinese family structure is fluid and dynamic and Chinese family structure has become more diverse with the occurrence of single-person families, singleparent families, as well as families with double income but no children, and cohabitant households, as living arrangements of choice. These changes both strengthen and challenge the families. The support from the extended family has served as a buffer.

The next four chapters discuss various issues related to mate selection and marriage in 
China. In Chapter 4, William Jankowiak reviews research on mate selection, intimacy, and marital love in China. He points out that Chinese society, as elsewhere, has constructed an often uneasy arrangement between the forces of passionate love, comfort love, and sexual desire. This arrangement requires continuous adjustment at both the individual and societal levels. The push and pull of feeling states and values common to the domains of love and sexual desire are seldom stable. This ensures that every generation will revisit, if not renegotiate, and thus modify the conventional explanation of how best to merge and thus integrate the pull toward emotional exclusiveness found in the impulse for love with an equally powerful concern for social and economic practicality. He assesses research findings as they pertain to changes found in mate selection criteria, competing rationales, and social negotiations, voiced and unvoiced within the context of courtship and dating, that range from starkly materialistic displays to private yearnings for the value of intimacy, and how the weight given that value has come to define what it means to have a satisfactory marriage.

In Chapter 5, Jing Song and Lulu Li study mate selection in rural China, stressing local variations, temporal change, and persisting patterns. They review three aspects of scholarship on mate selection in rural China: courtship and marriage formation, mate selection preferences, and mate selection markets. Although modernity and individuality are a general trend governing these three aspects, the persistence and revival of patriarchy and gender hierarchy are also evident. In the post-1978 era, market expansion and policy changes have led mate selection trends in different directions, such as increasing the 'girl power', reinforcing status homogamy, and intensifying the marriage squeeze. Some policy outcomes were unexpected, due to the complicated interaction of family structures, market forces, political factors, and gender norms. For rural people, marriage is not only increasingly entrenched with emotion and affection, but also an institution of status match.

In Chapter 6, Pan Wang examines Chinese-foreign marriages and divorces in the PRC from the late 1970 s to the 2000s onwards. She reviews the scholarly literature on Asia-West and intra-Asia marriages and studies of foreign-related marriages in China. She then analyses how Chinese-foreign marriages started to be resurrected thanks to China's economic liberation and legal reforms in the late 1970s. The early transitional period paralleled official recognition of, and public reservation against, Chinese-foreign marriages, especially marriages involving foreign nationals. The 1990s witnessed China's changing attitudes toward cross-Strait relations, reflecting in the proliferation of crossStrait marriages and the rising number of Chinese-foreign marriages overseas. China's increasing globalization in the 2000s triggered the growth in the number of foreign spouses and internationalized marriages in China, giving rise to gendered discourses and binary constructions in relation to foreign spouses of Chinese in the media. Wang concludes by summarizing the changing character of foreign-related marriages in different historical periods and argues that these marriages have begun to shape and complicate the overarching marriage landscape in China in this century.

In Chapter 7, Lijun Song, Rachel Skaggs, and Cleothia Frazier examine patterns of education homogamy in China, which refers to people's tendency to marry those with similar educational attainment. It is a crucial determinant of the distribution of various resources (social, economic, and cultural capital) and serves as a key mate selection criterion. Song, Skaggs, and Frazier summarize seven hypotheses can predict an increasing 
trend: educational homogenization, status attainment, educational legitimacy, economic inequality, promoted sameness, female economic attractiveness, and gender inequality. In contemporary China, the rapid educational expansion and the rising return to education may lend support to three hypotheses: educational homogenization, status attainment, and educational legitimacy. The increasing economic distances requires attention to the economic inequality hypothesis. Additionally, gender-related social factors play a role in spousal resemblance on education. The increasing gender segregation in occupations and earning differentiation calls for research on the gender inequality hypothesis. Finally, attention to the rural-urban divide is required in the study of educational homogamy, partly because of differences in the population structure and marriage patterns.

One unintended consequence of education homogamy is a female marriage squeeze in China. In Chapter 8, Arianne M. Gaetano studies a related issue, shengnu (剩女), which according to her is a derogatory label to describe educated, successful, unmarried urban women in their late twenties to mid-thirties in China. Gaetano argues that public attention to shengnu is conditioned by state regulatory power along with the market-driven media and commercial wedding industry. Shengnu is a discursive construct that simultaneously produces the social phenomenon that it purports to describe. It is also indicative of a general malaise and a conservative, patriarchal backlash wrought by recent challenges and changes to institutions of marriage, such as divorce and adultery, and of family, such as the one-child structure and ageing population, as well as in gender roles, particularly due to the increasing proportion of women in higher education and white-collar professions. The institutional or/and ideological influence on shengnu include state development policies and programmes; the marriage market rules of spouse selection and marital gift exchange; patterns and perceptions of marriage; family structure, gender, and intergenerational relations therein, and filial piety; gender role conflict between household and workplace; and reconfigured gender norms. These in turn relate to broader socioeconomic and cultural transformations of post-socialism, including ideologies of neoliberalism, privatization, and individualism; rising incomes and consumerism; urbanization and migration; and increasing social stratification.

In Chapter 9, Shuzhuo Li, Quanbao Jiang, and Marcus Feldman examine son preference and its effect on the male marriage squeeze in China. They first review the ruralurban and parity differences and the recent trend in China's sex ratio at birth (SRB). They also introduce an estimate of China's missing girls and investigate the male marriage squeeze together with the projected number of surplus males in the marriage market. Next, they discuss a number of issues related to marriage squeeze in China, including the increase in bride price and wedding expenses, increased bargaining power of females in the marriage market, female marriage migration, and 'bare branch' villages. Their empirical study is supported by rich data from China.

Lisa Eklund and Isabelle Attané also address the male marriage squeeze in China. However, their focus in Chapter 10 is an overview of previous studies on mate selection in China in the context of a marriage squeeze. They research the findings of these studies in relation to different theoretical perspectives on sex ratios and mate selection. Eklund and Attané deploy three theoretical lenses in analysing and furthering the understanding of how sex ratio imbalance and subsequent marriage squeezes impact upon mate selection: the demographic opportunity thesis, the sex ratio theory, and the institutional approach. They centre around three main themes, of mate selection for marriage purposes, mate 
selection for non-marital mate selection, and strategies men subject to a marriage squeeze deploy, as well as some consequences of these strategies. Eklund and Attané suggest that scholars can merge the sex ratio theory with an institutional approach to understand the marriage squeeze and mate selection in China. For example, the sex ratio theory posits that in high sex ratio societies, norms surrounding family and marriage are becoming more conservative and male-centric, and norms governing women's sexuality and behaviour are becoming more controlling due to men's structural power. Therefore, in the absence of a marriage squeeze, and a growing concern of being subject to one, it is possible that there would have been a reduction in marriage rates, a further delay in marriage, even higher divorce rates, and possibly more liberated sexual behaviour than is currently the case, even though as demonstrated here there is a positive relation between sex ratios and premarital and multi-partnered sex among women. This argument is possibly a potential reason for Chinese marriage rates and age at first marriage not following similar patterns to other low-fertility countries in East Asia.

The next two chapters examine family planning and fertility in China. In Chapter 11, Xiaotian Feng, Dudley L. Poston, and Xiaotao Wang discuss China's one-child policy and its effect on the changes in the Chinese family institution. They argue that since 1979 nearly 150 million single children have been born in China due to the one-child per family policy. It is believed that this generation of only children has dramatically changed the family structure, family relationships, and family lifestyle in China. It has also resulted in problems and issues not previously present in Chinese families, such as smaller families, a simplification of family structure, a shift from parent-centred families to child-centred families, changes in living patterns, and changes in family lifestyle. Also, there has been a decreased base of support for the elderly.

Stuart Gietel-Basten focuses on the effects of family planning on fertility in China in Chapter 12. He first reviews the history of Chinese family planning policy from the 1970s through to the implementation of a national two-child policy in 2016 . He then deconstructs the notion of an overarching national one-child policy which is the widely held impression of Chinese family planning policy, and takes a more in-depth look at regional patterns of family planning policy and fertility. Next, he presents some evidence that the one-child family may have become normalized in China. In other words, couples who are eligible to have more than one child are increasingly choosing to have only one. Finally, he considers other revolutionary changes in Chinese economy and society over the past four decades, and how these played a critical role in shaping past and current trends of fertility.

When it comes to the demographic features of Chinese families, substantial attention in both the academic and policy discourse has gone into detailing government's controversial family planning policies and citizens' pronounced preference for male offspring. In comparison, much less attention is directed to how the resulting family structures affect a host of household decisions as a child ages. This is both curious and disappointing since the consumption and savings decisions of Chinese households are currently emerging as a major factor shaping global economic development. In Chapter 13, Weili Ding examines the effects of fertility patterns on family finance in rural China. She surveys the interdisciplinary literature on family fertility and household finance and discusses an emerging literature that examines the experience in rural China. She summarizes evidence from studies using nationally representative data that explore a suite of household financial decisions including consumption, investment, remittance, and gift exchange, 
thereby presenting empirical evidence that the influences of offspring gender structure on household financial activities at various stages of a Chinese family's life cycle are both enormous and varied.

A major part of family financial spending in China is on human capital investments on children. In Chapter 14, Ming-Hsuan Lee reviews the literature on parental investment in children's human capital in China. The range of human capital can be very broad. Lee focuses her attention on formal education, that is, schooling in the government educational system. She identifies 11 important subjects in the literature and divides the literature into 11 categories based on the research focus of the studies. Specifically, categories 1-7 pertain to household characteristics and discuss how these household factors affect parental investment in children's human capital and cause educational inequality. Policy changes that affect households (such as the Compulsory Education Law and the one-child policy) are also discussed. Categories 8-10 pertain to outside factors and examine how these outside factors affect parental investment in children's human capital and cause educational inequality. Category 11 discusses the target of parental investment and its consequences. Finally, Lee discusses some issues when applying these accounts to future research on human capital investment on children in China.

In Chapter 15, Weiguo Zhang argues that familial relationships between adult children and their older parents are crucial to the well-being of older adults worldwide. In Chinese society, as elsewhere, adult children are the most important sources of emotional, instrumental, and financial support for elderly parents. Caring for childless older people has been an important concern in Chinese society since ancient times. With longer life expectancy and smaller family sizes in contemporary China, the Chinese population has been experiencing a rapid ageing process. There is evidence that the rate of infertility is rising, as more and more couples choose not to have children, millions may never be able to marry, and millions of parents have lost their single child. As a result, the number of Chinese childless seniors is on the rise. Further, individual pathways toward childlessness also vary. The psychological and physiological health of childless seniors has become a serious concern for scholars and practitioners alike. However, Zhang points out, research on childlessness and the well-being of childless seniors in China is limited. For example, we do not know how unmarriages and the adoption of children contributed to the prevalence of childlessness. Nor do we know how childless elders, be they infertile, unmarried, voluntarily childless, or having lost their children, differ in their physical and psychological well-being. Nor do we have a ready set of tools to improve the well-being of childless seniors. To narrow these knowledge gaps, Zhang reviews the scholarly literature on childlessness in China, focusing on the demography of childlessness and pathways toward childlessness, physical and psychological well-being of childless seniors, and individual coping strategies and social policy development in this chapter.

Of course, in China as in other parts of the world, the majority of senior citizens have children and they rely on their children for post-retirement well-being. There is variation in support from children due to a variety of factors such as gender and education. In Chapter 16, Haiyan Zhu discusses gendered patterns in financial support to parents in China. The role of family as a primary source of support for the elderly is important for ageing societies. This is particularly true in China, where filial piety is the central value of the family system and the majority of parents rely on their adult children, especially sons, for support. However, dramatic social, economic, and demographic changes have been 
eroding this traditional practice, thereby weakening intergenerational support between adult children and their parents. Zhu reviews recent research on children's financial transfer to parents, focusing on gendered patterns. Traditionally, sons are permanent family members and are expected to care for their natal parents throughout their lives, while daughters begin to contribute to their husbands' families upon marriage. Overall, research has shown a continuation of the traditional practice, especially in rural China and Taiwan, but also significant deviations, especially in urban China. Most notably, findings from research in urban China show that daughters now provide more financial support to their parents than sons do, suggesting that daughters are playing an increasingly important role in supporting the elderly in contemporary China. The urban-rural differences in the gendered pattern of intergenerational financial transfer suggest that economic factors may play an important role in changing the traditional family practice in mainland China.

Support to parents in old age from children is partly based on the extent of filial piety the children are committed to. In Chapter 17, Zhanlian Feng claims that the Confucian norm of filial piety has been the cornerstone of Chinese family. Under this cultural mandate, adult children have the moral responsibility for providing care and support, physically, financially, and emotionally, to their elderly parents. In China, the traditional family-based elder care system is being eroded by demographic shifts and socioeconomic changes in recent decades. China's population is ageing fast, and at the same time family size is shrinking and multigenerational households are waning. The availability of family caregivers is stretching thin, aggravated by increased population mobility and geographic dispersion of family members amid rapid urbanization and industrialization. Yet, China currently has a weak social safety net and is in the early stage of developing aged care services to meet the needs of an ever-increasing elderly population. Feng discusses the continuity and changes in the age-old tradition of filial piety in a fast-changing society. The interface between the family-centred old-age support system and emergent public policies to boost economic security and social services for the aged is also explored.

The above four chapters discuss parent-child interaction and focus mostly on its effect on parents' well-being and old-age security in China. Readers may begin to wonder what happens on the other side of the interaction. In Chapter 18, Jane Ribbens McCarthy and Ann Phoenix (with Guo Yu and Xiaoli Xu) address this interest by regarding childhood as a structural feature of the Chinese society that both fundamentally shapes, and is shaped by, children's everyday family lives. They then turn to a discussion of filial piety as a key cultural theme underpinning children's family lives and their intergenerational relationships. They also discuss particular aspects of contemporary parenting that might be said to relate to the theme of filial piety, namely empirical work on obedience and discipline. Next, they turn to a discussion of autonomy and independence as features of parenting that might be said to resonate with recent social policies and discourses of children's rights, and again review empirical work relevant to these themes. In this process, the authors highlight both conceptual and methodological issues in cross-cultural developmental psychology that are raised through this examination of empirical work. Finally, they conclude by pointing to the need to move beyond any straightforward dichotomy of themes and practices associated with filial piety, as opposed to those associated with children's rights.

Not every child in China is cared for by their parents, however. In particular, those with birth defects face a high risk of being abandoned after birth. So are female infants in 
rural areas. Some of the abandoned children are adopted by foreign adoptees. In Chapter 19, Monica Dowling studies international adoption from China. She reports that since China introduced its one-child policy in 1979, at least 150000 children, mostly girls, have left China through international adoption. For ten years between 1995 and 2005, China was one of the major countries from which children were adopted overseas. Dowling examines how particular aspects of globalization - that is, worldwide communication, the influence of international organizations, and economic inequalities in China - have continued to influence international adoption from China. She examines the factors that have contributed to the outcomes for Chinese adoptees and their adoptive parents, and for international non-governmental organizations and their staff based in China. She also explores cultural and historical attitudes toward population growth, child abandonment, and adoption, and reflects on how China's social, economic, and welfare policies have affected policies and practices concerned with 'the best interests of the child' in relation to international adoption and those left behind in state care in China.

In Chapter 20, Jiping Zuo examines marital construction of family decision-making power in China. In Western literature, family decision-making power is widely believed to be a strong indication of one's family status. Women are perceived as the powerless gender, given the predominance of the patriarchal family structure in world history. Therefore, women must increase their family decision-making power in order to raise their family status. Research on family patriarchy in mainland China, Hong Kong, and Taiwan in past decades has challenged this conventional wisdom in several ways. Zuo shows that since the 1990s, joint decision-making on major family affairs is not only the most common but also most preferred pattern among married couples. Women are often found to have greater power in routine financial management than men, but they do not necessarily consider it as an indication of their increased family status. Many women and men exercise family power to serve the family interest, sometimes at the expense of their own well-being. Even in pre-1949 China, married women became powerful matriarchs as they acquired mother-in-law status in a multigenerational patriarchal household, reversing their subordinate status as daughters-in-law. In addition, existing research on contemporary Chinese societies shows rural-urban differences, and differences between genders, in subjective evaluations of family power. The above patterns render Western theories and methods inadequate when applied to Chinese situations which are characterized by collective family settings rooted in agrarian economy and Confucius ethics, and modified by changing historical circumstances.

However, there is no guarantee that every Chinese couple can share family decisionmaking power rationally. If they cannot there will be marital disharmony, conflicts, or even the dissolution of marriage. In Chapter 21, Xiaohe Xu and Donna Miller examine marital instability in post-1978 China. Since the 1990s, a growing body of research on marital instability, including divorce, in the People's Republic of China has emerged. To synthesize this burgeoning body of research, this chapter develops five central themes drawn from empirical studies conducted in the reform and post-reform eras: the gender thesis, resource thesis, cultural-political thesis, life-course thesis, and psychological thesis. $\mathrm{Xu}$ and Miller show how individual characteristics, family backgrounds, and dyadic similarities/disparities (homogamy/heterogamy) and interactions are linked with marital dissatisfaction, marital conflict, and divorce among married Chinese respondents.

Unsurprisingly, some marital instabilities can result in tragedies. In Chapter 22, Jie 
Zhang discusses suicides among married women in rural China. The Chinese suicide rates used to be among the highest in the world, with about 23 suicide deaths every year for each 100000 Chinese population. Suicides by young females in rural China contributed substantially to the high rate of suicide and the total number of suicides, given the large number of people in China. Given the traditional familial structure that remains largely intact in rural China, Zhang reports that being married is not a protective factor for suicide in rural China. Fertility events are not related to suicide risk for rural young women. Social support is stronger for unmarried women than for married women, and risk factors tend to be family-related issues. Zhang accounts for rural young women's suicides in Chinese culture contexts, using Durkheim's notion of fatalistic suicide and the 'strain theory of suicide'.

In Chapter 23, Amy Y.M. Chow discusses bereavement and mourning in China. There are more than 10 million deaths in China each year. Assuming six persons are affected by each death, more than 60 million in China are facing the challenge of bereavement. Chow offers an overview of the phenomenon of death in China as well as the history of the development of leading theories in bereavement. She reviews various theories including process stage theories, coping theories such as the task model and dual process model, as well as psychopathological theories. She also outlines the accounts that cover the relational, constructivist, and neurobiological aspects of bereavement.

In Chapter 24, Howard Chiang provides a state-of-the-field overview of secondary scholarship on gender non-conformity in Chinese culture, and proposes three theoretical rubrics for imagining what we may call 'transgender Chinese studies'. He points out that because transgender studies is enabled and complicated by the indeterminacy of such key concepts as gender, sexuality, and transgender, the study of transgender China points to different possibilities of transforming the field vis-à-vis the very reorientations of these concepts. He argues that in the twenty-first century, the issue of kinship and the state sanction of queer unions have taken different Chinese societies by storm. Our imaginations of transgender China hold at least two significant implications for contemporary understandings of marriage, the family, and kinship. First, an individual's decision to undergo gender transitioning often involves tacit and cautious negotiations with immediate family members. Such a decision has profound effects on the daily routines of relatives. Second, the right of transgender individuals to marry in their acquired gender rather than their biological sex at birth has formed the basis of several legal battles in Taiwan, Hong Kong, and PRC. The present juncture should allow both gay and lesbian groups and transgender groups to fight together for a radical expansion and reorientation of the meanings of civil union and kinship, given their shared history of social oppression.

In Chapter 25, Wen-Shan Yang documents the changes in the family system in Taiwan. He shows that the values of Taiwanese traditional families were founded on the "fatherson-axis', characterized by a priority on family interests, an emphasis on hierarchy and birth order, women's subordinate status, patrilineal descent, the pursuit of family growth, and the maintenance of a big family system. While some of these characteristics have persisted, families in Taiwan have been increasingly based on a 'husband-wife-axis' due to the expansion of compulsory education and higher education as well as the rise in women's self-awareness and labour participation rates. Relatedly, late or no marriage, late or no pregnancy, and increased divorce rates have emerged in Taiwan society, influencing the power and status of marriage and the family institution in Taiwan. 
In Chapter 26, Kwok-fai Ting claims that the family played a crucial role in buffering risks and social problems that came with social transformation in Hong Kong. The utilitarianistic aspect of traditional familism was emphasized in the course of Hong Kong's industrialization, helping families to consolidate resources to cope with market uncertainties. Equally importantly, the British colonial government had little intention to alter the Chinese way of life other than maintaining law and order in the territory, helping Hong Kong to preserve much of its cultural heritage. Thus, although Western values and lifestyles have been introduced to Hong Kong, some traditional Chinese customs have persisted. Ting then traces marriage statistics back to the reconstruction period immediately after World War II, in an attempt to establish a long-term view on marriage behavior since 1945. Next, he shows that the demographic factor has only a marginal effect on marriage timing, and it does explain unmarried rates, suggesting that non-marriage does not necessarily reflect desirability of marriage. Poverty deferred marriage plans and raised unmarried rates, particularly among men because of their breadwinner role, in pre-industrialized Hong Kong. However, prosperity did not lead to early marriage and lower unmarried rates since the 1990s, suggesting that income is certainly not the only major factor at play. Higher expectations on wedding arrangements and accommodation after marriage do not adequately explain the recent surge in unmarried rates, as materialistic demands may delay but not deter marriage. The expansion of education, particularly at the tertiary level, may lead to the postponement of marriage, but it is also possible that the high unmarried rates may indicate greater difficulties for educated women to find a matching partner because of the persistence of hypergamy. Career ambition among young women may not explain the high unmarried rates since the millennium because there were simply not enough high-paying jobs for women before the 1990s to distract them from pursuing marriage, and ending up being single at their late forties.

In sum, while this volume does not raise or examine new questions for the literature on marriage and the family in China, it advances this scholarship significantly in two aspects. First, it consolidates knowledge scattered in different disciplines and provides readers with a multidisciplinary and multifaceted coverage of major issues in the family and marriage in one single volume. Second, it addresses some conceptual, theoretical, and methodological issues in the study of marriage and the family in China and offers critical reflection on where the field has been and where it is going. The contributors of this volume have examined how state policy, market reforms, and traditional ideas and new concepts have affected marriage and the family in China. They have turned this edited volume into a convenient reference, offering an overview of key issues in research on marriage and the family in China. Hopefully, this volume will enrich knowledge on marriage and the family in China and become a key reference in future research on family institutions in China.

\section{REFERENCES}

Berman PW, O'Nan BA, and Floyd W (1981) The double standard of aging and the social situation. Sex Roles 7(2): 87-96.

Bradbury M, Peterson MN, and Liu JG (2014) Long-term dynamics of household size and their environmental implications. Population and Environment 36(1): 73-84.

Buss DM, Abbott M, Angleitner A, et al. (1990) International preferences in selecting mates. Journal of CrossCultural Psychology 21(1): 5-47. 


\section{Handbook on the family and marriage in China}

Cai Y (2010) China's below-replacement fertility. Population and Development Review 36(3): 419-440.

Cai Y (2013) China's new demographic reality. Population and Development Review 39(3): 371-396.

Chen FN and Short SE (2008) Household context and subjective well-being among the oldest old in China. Journal of Family Issues 29(1): 1379-1403.

Coale AJ (1989) Marriage and childbearing in China since 1940. Social Forces 67(4): 833-850.

Cohen M (1976) House United, House Divided. New York: Columbia University Press.

Connelly R and Maurer-Fazio M (2016) Left behind, at-risk, and vulnerable elders in rural China. China Economic Review 37(1): 140-153.

Cox FD (2008) Human Intimacy. Belmont, CA: Wadsworth Publishing.

Davis DS (2014) Demographic challenges for a rising China. Daedalus 143(2): 26-38.

Dion KK and Dion KL (1993) Individualistic and collectivistic perspectives on gender and the cultural context of love and intimacy. Journal of Social Issues 49(3): 53-59.

Eastman LE (1988) Family, Fields, and Ancestors. New York: Oxford University Press.

Feng JX, Dijst M, Wissink B, and Prillwitz J (2015) Elderly co-residence and the household responsibilities hypothesis. Urban Geography 36(5): 757-776.

Feng ZX, Jones K, and Wang WF (2015) An exploratory discrete-time multilevel analysis of the effect of social support on the survival of elderly people in China. Social Science and Medicine 130(2): 181-189.

Fincher LH (2012) China's 'Leftover' women. Available at http://www.nytimes.com/2012/10/12/opinion/global/ chinas-leftover-women.html?_r=1\&.

Fincher LH (2014) Leftover Women. London: Zed Books.

Freedman M (1979) The Chinese domestic family. In: Freedman M (ed.) The Study of Chinese Society. Stanford, CA: Stanford University Press, 235-239.

Goode W (1963) World Revolution and Family Patterns. New York: Free Press.

Han HY (2010) Trends in educational assortative marriage in China from 1970 to 2000. Demographic Research 22: $733-770$.

Hou JW and Li KW (2011) The aging of the Chinese population and the cost of health care. Social Science Journal 48(3): 514-526.

Huang KS (2014) Marriage squeeze in China. Journal of Family Issues 35(12): 1642-1661.

Jackson T, Chen H, Guo C, and Gao X (2006) Stories we love by. Journal of Cross-Cultural Psychology 37(4): 446-464.

Ji Y (2015) Between tradition and modernity: 'leftover' women in Shanghai. Journal of Marriage and Family 77(5): 1057-1073.

Ji YC and Yeung WJ (2014) Heterogeneity in contemporary Chinese marriage. Journal of Family Issues 35(12): $1662-1682$.

Jiang QB and Sánchez-Barricarte JJ (2012) Bride price in China. History of the Family 17(1): 2-15.

Jiang QB, Sánchez-Barricarte JJ, Li SZ, and Feldman MW (2011) Marriage squeeze in China's future. Asian Population Studies 7(3): 177-193.

Lang O (1946) Chinese Family and Society. New Haven: Yale University Press.

Lee JZ and Campbell CD (1998) Headship succession and household division in three Chinese banner serf populations, 1789-1909. Continuity and Change 13(1): 117-141.

Lee JZ and Gjerde J (1986) Comparative household morphology of stem, joint, and nuclear household systems. Continuity and Change 1(1): 89-111.

Li YS (2005) The challenges of aging toward Chinese society. Public Administration and Management 1(3): 248-268.

Lin WY (2014) Challenges of long-term care provisions for the elderly in urban China. China - An International Journal 12(2): 144-160.

Liu JY (2014) Ageing, migration and familial support in rural China. Geoforum 51: 305-312.

Liu L, Dong XY, and Zheng XY (2010) Parental care and married women's labor supply in urban China. Feminist Economics 16(3): 169-192.

Liu T and Zhang XY (2009) Ratio of males to females in China. British Medical Journal 338, article b483.

Lu R (2014) The diminished family unit. Available at http://articles.chicagotribune.com/2014-05-22/opinion/ctchina-family-smaller-perspec-0522-20140522_1_family -planning-commission-development-report-chinese.

Magistad MK (2013) China's 'leftover women', unmarried at 27. Available at http://www.bbc.com/news/maga zine-21320560.

Morgan SP, Guo ZG, and Hayford SR (2009) China's below-replacement fertility. Population and Development Review 35(3): 605-629.

Mu Z and Xie Y (2014) Marital age homogamy in China. Social Science Research 44(1): 141-157.

Parish, W and Whyte M (1978) Village and Family in Contemporary China. Chicago, IL: University of Chicago Press.

Pimentel EE (2000) Just how do I love thee? Journal of Marriage and the Family 62(1): 32-48.

Qian Y and Qian ZC (2014) The gender divide in urban China. Demographic Research 31(45): 1337-1364. 
Qiao FB, Rozelle S, Zhang LX, Yao Y, and Zhang J (2015) Impact of childcare and eldercare on off-farm activities in rural China. China and World Economy 23(2): 100-120.

Retherford R, Choe MK, Chen JJ, and Cui HY (2005) How far has fertility in China really declined? Population and Development Review 31(1): 57-84.

Shen SY, Li F, and Tanui JK (2014) Long-term care insurance in China. Social Work in Health Care 53(7): 679-692.

Simpson P and De Lacey M (2013) Chinese men want wives who are easier to control. Available at http://www.dai lymail.co.uk/femail/article-2285865/Chinese-men-want-wives-easier-control-How-Chinas-high-flying-single-w omen-rejected-male-suitors-intimidated-successes.html.

Song LJ (2009) The effect of the Cultural Revolution on educational homogamy in urban China. Social Forces 88(1): 257-270.

Sontag S (1972) The double standard of aging. Available at http://www.unz.org/Pub/SaturdayRev-1972sep 23-00029.

Statista (2016) Average number of people living in households in China from 1990 to 2013. Available at http:// www.statista.com/statistics/278697/average-size-of-households-in-china/.

Subramanian S and Lee D (2011) For China's educated single ladies, finding love is often a struggle. Available at http://article.yeeyan.org/compare/225866.

Sun A and Zhao YH (2016) Divorce, abortion, and the child sex ratio. Journal of Development Economics 120(1): 53-69.

To S (2013) Understanding Sheng $N u$ ('leftover women'). Symbolic Interaction 36(1): 1-20.

To S (2015) My mother wants me to jiaru-haomen (marry into a rich and powerful family)! Sage Open 5(1): 1-11.

Wang XL, Shang XY, and Xu LP (2011) Subjective well-being poverty of the elderly population in China. Social Policy and Administration 45(6): 714-731.

Wolf AP (1980) Marriage and Adoption in China, 1845-1945. Stanford, CA: Stanford University Press.

Wolf M (1985) Revolution Postponed. Stanford, CA: Stanford University Press.

Wu XG, Ye H, and He G (2014) Fertility decline and women's status improvement in China. Chinese Sociological Review 46(3): 3-25.

$\mathrm{Xu}$ AQ and Yan X (2014) The changes in mainland Chinese families during the social transition. Journal of Comparative Family Studies 45(1): 31-53.

Yang CY, Fu HQ, and Li L (2016) The effect of family structure on female labor participation. Asian Social Work and Policy Review 10(1): 21-33.

Zang XW (1993) Household structure and marriage in urban China. Journal of Comparative Family Studies 24(1): $35-43$.

Zang XW (2007) Family, marriage, and kinship. In: Gamer R (ed.) Understanding Contemporary China. Boulder, CO: Lynn Rienner Publishers, 281-308.

Zeng Y and Wang ZL (2003) Dynamics of family and elderly living arrangements in China. China Review 3(2): 95-119.

Zhang SY and Kline SL (2009) Can I make my own decision? Journal of Cross-Cultural Psychology 40(1): 3-23.

Zhang W, Feng QS, Liu L, and Zhen ZH (2015) Social engagement and health. International Journal of Aging and Human Development 80(4): 332-356.

Zheng ZZ, Yong C, Wang F, and Gu BC (2009) Below-replacement fertility and child-bearing intention in Jiangsu province, China. Asian Population Studies 5(3): 329-347.

Zhou DM (2006) Follow-up investigations of Phoenix Village. Chinese Sociology and Anthropology 38(2): 17-31.

Zhu WX, Lu L, and Hesketh T (2009) China's excess males, sex selective abortion, and one child policy. British Medical Journal 338, b1211. 